\title{
Stand structure-dependent mass-ratio and complementarity effects simultaneously drive aboveground biomass in temperate Quercus forests
}

\author{
Wen-Qiang Gao ${ }^{1}$, xiangdong lei ${ }^{1}$, Dong-Li Gao ${ }^{1}$, and Yu-Tang $\mathrm{Li}^{2}$ \\ ${ }^{1}$ Chinese Academy of Forestry \\ ${ }^{2}$ Jilin Forestry Inventory and Planning Institute
}

May 28, 2021

\begin{abstract}
Aim: Forests play a key role in regulating the global carbon cycle, a substantial portion of which is stored in aboveground biomass (AGB). It is well-understood that biodiversity can increase the biomass through complementarity and mass-ratio effects, and the contribution of environmental factors and stand structure attributes to AGB was also observed. However, the relative influence of these factors in determining the AGB of Quercus forests remains poorly understood. Location: Temperate Quercus forests in northeastern China. Methods: Using a large dataset retrieved from 523 permanent forest inventory plots across Northeast China, we examined the effects of integrated multiple tree species diversity components (i.e., species richness, functional and phylogenetic diversity), functional traits composition, environmental factors (climate and soil), stand age, and structure attributes (stand density, tree size diversity) on AGB based on structural equation models. Results: We found that species richness and phylogenetic diversity both were not correlated with AGB. However, functional diversity positively affected AGB via an indirect effect in line with the complementarity effect. Moreover, the community-weighted mean of specific leaf area and height increased AGB directly and indirectly, respectively; demonstrating the mass-ratio effect. Furthermore, stand age, density, and tree size diversity were more important modulators of AGB than biodiversity. Main conclusions: Our study highlights that biodiversity-AGB interaction is dependent on the regulation of stand structure that can be even more important for maintaining high biomass than biodiversity in temperate Quercus forests.
\end{abstract}

\section{Hosted file}

Manuscript_Quercus forest.doc available at https://authorea.com/users/416516/articles/524033stand-structure-dependent-mass-ratio-and-complementarity-effects-simultaneously-driveaboveground-biomass-in-temperate-quercus-forests 